\title{
Discussions on PV power Parity
}

\author{
Q.h. YUAN* \\ Guangdong University of Science \& Technology, Dongguan523083, China
}

\begin{abstract}
China is the biggest coal country. However, China's power industry relies heavily on fossil energy, which seriously threatens China's energy security. It is unreasonable to use the current coal power price as a benchmark for parity. At present coal power price has not accounted for various emissions tax and the resource tax. so authentic parity must be fully included in resource costs and environmental costs. Fair pricing is the primary prerequisite for parity. Nowadays the biggest obstacle for the PV industry today is not technology, but the unreasonable price mechanism. The explore of photovoltaic electricity price as the benchmark electricity price can accelerate the development of the photovoltaic industry, can accelerate the green revolution of energy production, can also accelerate the construction of ecological civilization. Therefore, it is imperative to adopt PV power prices as a benchmark for parity in China as soon as possible.
\end{abstract}

\section{Introduction}

China is the biggest coal country. For a long time, coal-fired power generation has played an important role in supporting China's modernization. However, China's power industry relies on fossil energy, which seriously threatens China's energy security. In 2019, China's total energy consumption reached 4.86 billion tce, of which coal, oil and natural gas accounted for $57.7 \%, 19.3 \%$ and $8.1 \%$ respectively[1], and fossil energy accounted for $85.1 \%$. China has become a net energy importer since 1992. Energy imports have increased from 20 million toe in 1992 to about 1 billion toe in 2019 , and the overall external dependence has reached $21 \%$. In China the exploitable life of the three energy sources is 18.7 years for oil, 37 years for coal and 47.3 years for natural gas[2]. The total $\mathrm{R} / \mathrm{P}$ ratio of the 3 major fossil energy sources weighted by their current consumption ratio is only 28.8 years. Due to the three fossil energy self-sufficiency rates are $79 \%$, China's total $\mathrm{R} / \mathrm{P}$ ratio of the three fossil fuels is only 22.7 years, less than the average $\mathrm{R} / \mathrm{P}$ ratio of the world(64.2 years).

The proportion of fossil energy in the power industry is too high, which has led to a severe energy saving and emission reduction situation in China. Until the end of 2019 , the national installed capacity of power generation was $2010.6 \mathrm{GW}$, of which nearly $50 \%$ were thermal power units. Coal-fired power generation units accounted for $1040.63 \mathrm{GW}$, and gas power was $90.24 \mathrm{GW}$. Although the proportion of coal-fired power generation installed capacity in China has dropped from $73.8 \%$ in 2010 to $51.8 \%$ in 2019 , and the proportion of power generation has dropped from $81.4 \%$ in 2010 to $62.2 \%$ in 2019 , it is still much higher than the current world coal-fired power generation the mean proportion of $38 \%$. In 2019, China's natural gas power generation accounted for only $3.2 \%$, far below the world average of $23.2 \%$. The national thermal power smoke dust, sulfur dioxide, nitrogen oxide, and CO2 emissions are about 180,000 tons, 890,000 tons, 930,000 tons, and 4.23 billion tons respectively[3]. More than half of China's total $\mathrm{CO} 2$ and $\mathrm{SO} 2$ emissions come from the thermal power industry. So optimizing the power supply structure and achieving clean, low-carbon and green development is not only an essential requirement for promoting the energy revolution, but also an inevitable requirement for achieving sustainable development.

The electricity price reform is the core and prerequisite of the electricity market reform [4]. Only the correct price mechanism can guide healthy competition in the market and realize the optimal allocation of resources. If the price system itself is unreasonable, then the operation of the market will be deformed. China has set a clear goal of electricity price reform, that is to ensure that the country's electricity prices are reasonable, the procedures are standardized, and the price formation mechanism is transparent. Since the National Development and Reform Commission, the Ministry of Finance, and the National Energy Administration issued the "Notice on Matters Related to Photovoltaic Power Generation in 2018" on May 31 2018, parity on-grid has become a hot topic in the power industry. The intention is to decline through subsidies. Forcing the cost of renewable energy power generation to be close to that of coal power.

\section{Coal power is the benchmark for electricity prices in China}

Electricity is a product with zero inventory, real-time production, real-time consumption, and dynamic balance. If there is no adjustment tool, it is prone to violent

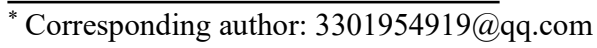


fluctuations. Therefore a healthy electricity market must control electricity prices. Benchmarking is the benchmark of China's electricity price system. Since the benchmark on-grid tariff for coal power generation was first approved in 2004, the country has undergone 12 adjustments, including 7 upward adjustments, 4 downward adjustments, and one increase and decrease [4,5]. China's electricity price system based on coal-fired power is basically finalized. At present, China's electricity sales price is composed of on-grid electricity price (49\%), transmission and distribution price $(30 \%)$, value-added tax (14\%), government funds and surcharges (4\%) and line Loss (3\%). According to the bulletin, the national average on-grid electricity prices in 2019 were: coal power 0.37 yuan $/ \mathrm{kWh}$, wind power 0.53 yuan $/ \mathrm{kWh}$, and photovoltaic 0.86 yuan/kWh[6].

According to the latest requirements issued by the National Development and Reform Commission, starting from January 1, 2020, the coal-fired power generation benchmark on-grid tariff mechanism will be changed to a market-based pricing mechanism of "base price + fluctuation". The benchmark price is determined according to the current local coal power benchmark price, including desulfurization, denitrification, and dust removal. On this basis, the price of electricity can be allowed to float (rise no more than $+10 \%$, fall no more than $-15 \%)$. The previous single benchmark electricity price has changed to a floating electricity price, and the 16-year coal-fired power generation benchmark on-grid electricity price mechanism has come to an end. The direction of the market-oriented reform of the electricity system is more clear, but the total fluctuation of upper and lower prices does not exceed $25 \%$, so floating electricity prices are around the current local coal power benchmark electricity prices fluctuate slightly. Therefore coal power benchmark on-grid tariffs are still the "anchor" of China's electricity prices.

\section{The premise of parity is fair pricing}

Electricity is a highly standardized energy commodity, and the market economy inevitably requires the price to be basically unified and a price benchmark. But why use coal power as a benchmark? The various feed-in tariff standards in China in 2019 are shown in Table 1. The current fossil energy prices seem to have a great competitive advantage.

However, this price comparison ignores the fundamental difference between fossil energy and non-fossil energy: fossil energy is non-renewable, and non-fossil energy is renewable[7]. As a fossil energy source, every minute mined will reduce a point, and as a non-fossil energy source, it does not reduce a point when used. It can be seen that the essence of fossil energy production is that mankind obtains "stock" energy from nature by mining limited resources, and using one point consumes three points, it is "negative energy" in general; while renewable energy uses technology and equipment to create "incremental" energy, and using one point is one point, it is "positive energy" overall. These two energy production methods are fundamentally different[8]. The current price of coal is basically priced according to "cost + appropriate profit", but due to historical reasons of coal pricing, the cost here does not include the cost of resources and environmental pollution. Nowadays the mining life of coal in China is only 38 years. Oil and Natural gas is shorter. So once the coal is exhausted after 38 years, can coal be purchased at a higher price?

Human mining of coal is only nature's "porter", not creating energy. If the previous pricing method is used, it is unreasonable to price resource-based products only based on labor costs. At present the energy efficiency of coal-fired power generation into households is only $1 / 3$, which means that only $1 \mathrm{kwh}$ can be used when consuming $3 \mathrm{kwh}$ of energy. This kind of "wasteful", "low efficiency" energy utilization method it is not sustainable and cannot be used as a price benchmark in the energy market, otherwise it will inevitably lead to market deformities. Renewable energy, because it does not reduce any resources, so the use of renewable energy is suitable for labor cost pricing.

China's new Resource Tax Law has been implemented from September 1, 2020, the resource tax rate for coal is $2-10 \%$, generally $5 \%$ [9]. Can such a low tax rate effectively protect resources? Obviously not. So how to impose a resource tax on non-renewable fossil energy? Energy consumption tax can be levied by using the energy equivalent method. For example, coal-fired power generation, calculated according to the efficiency of coal-fired power generation is $42.8 \%$ in 2018. Each kwh of electricity(123gce) will consume about $2.3 \mathrm{kwh}$ of energy (290gce). Then consider the loss of coal mining, coal transportation, and power transmission. Each kwh used by the user terminal consumesabout $2.9 \mathrm{kwh}$ (356gce ), so the household energy efficiency in 2018 is only $34.5 \%$, as shown in Table 2 below. It can be seen that $1 \mathrm{kWh}$ of electricity consumed by residents consumes about $2.9 \mathrm{kWh}$ of electricity. Then how much is the value of the lost $1.9 \mathrm{kWh}$ ? If the price of $1 \mathrm{kWh}$ is 0.3 yuan, then the loss of $1.9 \mathrm{kwh}$ is worth about 0.57 yuan, that is consumers should also pay for the loss of $1.9 \mathrm{kwh}$ in the whole process, which is equivalent to 0.57 yuan $/ \mathrm{kWh}$ according to the value of the lost energy consumption tax. The use of renewable energy such as hydropower, wind power, and photovoltaics will not lead to resource depletion, so there is no need to levy resource taxes.

Table 1. The various electricity feed-in tariff standards in China in 2019 (Yuan/kwh)

\begin{tabular}{ccccccccccc}
\hline $\begin{array}{c}\text { coal } \\
\text { power* }\end{array}$ & $\begin{array}{c}\text { Hydro } \\
\text { power }\end{array}$ & $\begin{array}{c}\text { Onshore } \\
\text { wind }\end{array}$ & $\begin{array}{c}\text { Offsh } \\
\text { ore } \\
\text { wind }\end{array}$ & PV & $\begin{array}{c}\text { CS } \\
\text { P }\end{array}$ & LG power & $\begin{array}{c}\text { Biogas } \\
\text { power }\end{array}$ & $\begin{array}{c}\text { Biomass } \\
\text { power }\end{array}$ & $\begin{array}{c}\text { nuclea } \\
\text { r } \\
\text { power }\end{array}$ & Waste \\
power \\
\hline 0.25 & 0.2632 & $0.29-$ & $0.75-$ & $0.4-$ & 1.1 & $0.3879-$ & $0.485-$ & 0.75 & 0.3717 & 0.65 \\
0.4993 & -0.48 & 0.47 & 0.85 & 0.55 & 5 & 0.772 & 0.689 & & -0.464 & \\
\hline
\end{tabular}

*:coal power price including desulfurization, denitrification, and dust removal. 
Table 2. Life cycle energy efficiency of coal-fired power generation in China (\%)

\begin{tabular}{cccccc}
\hline $\begin{array}{c}\text { coal } \\
\text { mining }\end{array}$ & $\begin{array}{c}\text { Coal } \\
\text { transportation }\end{array}$ & $\begin{array}{c}\text { power } \\
\text { generation }\end{array}$ & $\begin{array}{r}\text { Power } \\
\text { plant }\end{array}$ & $\begin{array}{r}\text { Power } \\
\text { grid }\end{array}$ & $\begin{array}{r}\text { Total energy } \\
\text { efficiency }\end{array}$ \\
\hline 96.68 & 95.10 & 42.82 & 93.36 & 93.97 & 34.54 \\
\hline
\end{tabular}

In addition, fossil energy power generation will have emissions, such as soot, sulfur dioxide, nitrogen oxides, $\mathrm{CO} 2$, etc. The emissions of these pollutants have a certain environmental cost. For these pollutants, although part of the pollution fee (or environmental tax) has been levied, China currently does not levy $\mathrm{CO} 2$ tax, and it exempts thermal power plants that meet the emission standards of smoke, sulfur dioxide, and nitrogen oxides. Environmental protection taxes are not fully in place, which is unfair [10]. True parity must be fully included in resource costs and environmental costs, that is, fair pricing is the primary prerequisite for parity. So fossil energy consumption must consider environmental costs. According to Xu Weili' s 2014 research, the production cost of coal power is 0.4752 yuan $/ \mathrm{kwh}$, but the environmental cost of coal power is as high as 0.555 yuan $/ \mathrm{kw}$, that is the environmental cost of coal power is 0.08 yuan higher than the production cost [11]. According to Zhao Xiaoli's research, the environmental external cost of thermal power generation in 2016 is $0.12 \sim 0.19$ yuan $/ \mathrm{kWh}$. The external cost of $\mathrm{CO} 2$ generated by the thermal power industry is 0.04 yuan $/ \mathrm{kWh}$ (calculated at 30.97 yuan/ton, which is less than $10 \%$ of the cost of $\mathrm{CO} 2$ capture and collection(CCS)) $[12,13]$. So the carbon tax should be levied as soon as possible, and the carbon tax should be close to the operating cost of CCS. Only in this way can speed up the popularization of CCS and promot its price reduction. It can be seen that if considering the environmental costs and resource costs of fossil energy consumption, renewable energy such as photovoltaics has already had a price advantage. Of course if the use of renewable energy also generates emissions, it must also be included in the environmental cost of the emissions.

\section{PV power should be the new benchmark for electricity prices}

The complete life cycle of coal power is not "from mine to socket", but also includes the process of plant carbon fixation and geological formation of coal. Therefore, coal is also the crystallization of sunlight. The energy conversion efficiency should be compared according to the unified process "from sunlight to socket". According to Zhu Wenquan's actual measurement data using 690 observation points across the country, it is concluded that the maximum light energy utilization rate of 10 typical vegetations in China is between 0.389-0.985gC/MJ, while Peng Shaolin set the maximum light energy utilization rate of Guangdong vegetation as $1.25 \mathrm{gC} / \mathrm{MJ}[14]$, calculated according to the vegetation light energy utilization rate of $0.4-1.5 \mathrm{gC} / \mathrm{MJ}$, the energy efficiency of plant photosynthesis carbon fixation is $1.1-4.3 \%$, and then coal-fired power generation, the final terminal energy efficiency is $0.41-1.54 \%$, then " In the process of energy utilization from sunlight to socket, the energy efficiency of photovoltaic power generation products is 13-49 times that of coal power (calculated based on the energy efficiency of photovoltaic power generation products of $20 \%$ ), so "from sunlight to socket", photovoltaic power generation efficiency is dozens of times higher than that of coal power. Therefore, in accordance with the principle of priority to market competition efficiency, photovoltaic power generation should be prioritized with coal power generation. The above comparisons are theoretical calculations, but the process of geological coal formation lasts for millions of years, and it is basically impossible to regenerate it, so coal is a non-renewable resource. So it must be strictly protected through a resource tax.

Starting in 2019, photovoltaic power generation has implemented a bidding policy under the "guided electricity price". The benchmark electricity price for photovoltaics in 2020 is $0.35 \sim 0.49$ yuan $/ \mathrm{kWh}$, and the actual winning price range is $0.2427 \sim 0.4493$ yuan $/ \mathrm{kWh}$. According to the calculation of the average cost of photovoltaics in 2020 and the benchmark electricity prices for coal burning in various regions, nearly $80 \%$ of China's regions can achieve a parity economy, the rate of return is over $8 \%$. Except for Chongqing, the cost per kilowatt-hour (LCOE) of photovoltaic parity projects in all regions of China has been lower than the local coal-fired electricity price. In Portugal and the UAE, the lowest electricity price for tendered projects in 2019 has been lower than 2 cents $/ \mathrm{kWh}$, which is already lower than the 3.7 cents $/ \mathrm{kWh}$ of Xinjiang, the province with the lowest coal-fired benchmark electricity price in China[15,16].

Nowadays photovoltaic power generation could been widely popularized and blossomed everywhere. In the past decade the price of photovoltaic modules and system costs have dropped by more than $90 \%[17,18]$. It can be seen that the cost of photovoltaic power generation is already lower than that of coal power in many places, and photovoltaic power generation has made an important contribution to achieving parity in China and the world. Photovoltaic power generation is becoming the benchmark for electricity prices in China and the world. At present, the benchmark of "parity" is still coal power, but the price of coal power does not fully include various emission taxes, nor does it include resource taxes. So it is unreasonable to use the current coal power price as a benchmark for parity.

Since 2021, photovoltaic projects other than wind power and household photovoltaics will be fully subsidized, entering the era of parity. This is a major milestone in China electricity prices. In fact, if pricing is done fairly and reasonably, wind power and photovoltaic 
power prices will have long been lower than coal power prices, and they should have long been used as benchmarks for electricity prices. Therefore fair pricing is more important than parity. Renewable energy power generation will neither deplete resources nor produce emissions, that is, there is no resource cost and environmental cost. So renewable energy power generation can be used as a true benchmark for electricity prices, thus accelerating the pace of renewable energy development.

\section{Conclusion}

To reform the current coal power benchmarking mechanism as soon as possible, and to explore the use of photovoltaic power prices as benchmark power prices to be more fair and reasonable, has significant positive significance as followeed:

1. Speed up the development of the photovoltaic industry. In recent years the decline of photovoltaic subsidies has accelerated, and the entire photovoltaic industry is struggling. Photovoltaic power generation has even been ridiculed as "defrauding government subsidies." In fact, the price of photovoltaic power is already much lower than that of coal power. China Coal and Electricity has not yet levied a carbon emission tax, and the resource tax rate is too low. Once the levy is in place, the photovoltaic power price will be extremely competitive in the market, which will inevitably greatly accelerate the enthusiasm of the whole people for photovoltaic investment and further accelerate the development of the photovoltaic industry.

2. Accelerate the green revolution in energy production. As the cost of hydropower and wind power is lower, photovoltaics be used as a benchmark for electricity prices, can also accelerate the rapid development of hydropower, wind power, photovoltaics and other renewable energy technologies and market applications. Renewable energy is pollution-free and non-exhaustive green electricity. If it can accelerate its development, it will inevitably speed up the "two alternatives" of energy production, namely electric energy substitution (electric energy instead of fossil energy) and clean substitution (clean energy instead of fossil energy),and speed up the green revolution in energy production.

3. Promote the construction of ecological civilization. The core of the modern energy system must be green power. So the green revolution in energy production will inevitably promote the green and sustainable development of the economy and society, thereby accelerating China's ecological civilization and the construction of a beautiful China.

Thank GDST Research Foundation (GKY-2020KYYBK-7).

\section{References}

1. Electric Power Planning and Design Institute. China Energy Development Report 2019. Beijing: China Electric Power Press. 2020.
2. BP Statistical Review of World Energy 2020 [EB/OL] .https://www.bp.com/en/global/corporate/en ergy-economics/statistical-review-of-world-energy.ht $\mathrm{ml}$, June. 2020.

3. China Electricity Council, China Electricity Industry Annual Development Report 2020, http://www.chinapower.com.cn/zx/zxbg/20200615/22 414.html.2020.06

4. Li Jiexuan,Wang Shiye.The current problems in China's electricity price regulation and foreign experience for reference.

Price Monthly,2018(08):17-22.DOI:10.14076/j.issn. 1006-2025.2018.08.04.

5. Bai Mei.The high-quality development of China's power industry: goals, opportunities, challenges, and realization paths-the new China's power industry starts again in the glorious 70 years[J].Price Theory and Practice,2019(07):4-9+162.DOI:10.19851/j.cnki. cn11-1010/f.2019.07.001.

6. National Energy Administration. 2019 National Electricity Price Regulatory Bulletin.

http://www.nea.gov.cn/2020-11/05/c_138530255.htm

7. Zheng Xinye, $\mathrm{Wu}$ You.Innovation of price mechanism to promote green development of energy system $[\mathrm{J}]$.Price Theory and Practice,2018(04):12-16.DOI:10.19851/j.cnki.cn11-1 010/f.2018.04.003.

8. Li J.F,Jiang S.y, Reflection on energy Security in the Era of Transition and China's Plan.ENERGY OF CHINA,2020,42(01):4-10. DOI: $10.3969 /$ j.issn.1003-2355.2020.01.001.

9. State Administration of Taxation, Resource Tax Law of the People's Republic of China, http://www.chinatax.gov.cn/chinatax/n810341/n8107 55/c5136082/content.html.

10. Shi Dan.The characteristics, difficulties and key points of the current energy price reform $[\mathrm{J}]$. Price Theory and Practice,2013(01):18-20.

11. Xu Weili, Li Yanan, Wang Huajun.Comparative analysis of the complete cost of coal-fired thermal power and wind power[J]. Wind Energy,2014(06):50-55.

12. Zhao Xiaoli,Cai Qiong,Hu Yanan.Analysis of Environmental External Costs of China's Thermal Power Industry[J].Journal of Beijing Institute of Technology (Social Sciences Edition), 2016,18(01):10-17.

DOI:10.15918/j.jbitss1009-3370.2016.0102.

13. Gao Hua. Global Carbon Capture and Storage (CCS) Technology Status and Application Prospects. Coal Economic Research.2020.40.(05):33-38. DOI : 10.13202/j.cnki.cer.2020.05.005.

14. Bao Gang,Xin Xiaoping,Bao Yuhai,Wang Mulan, Yuan Zhihui,Ulan Tuya.Optimization of the Maximum Light Energy Utilization Value of Inner Mongolia Grassland Vegetation[J].Spectroscopy and

\footnotetext{
*Corresponding author: 3301954919@qq.com
} 
Spectral Analysis, 2016, 36(10):3280-3286 . DOI:10.3964/j.issn.1000-0593(2016)10-3280-07.

15. Wang Sicheng. The Future of China's Photovoltaic Industry $2020[\mathrm{~EB} / \mathrm{OL}]$.

https://news.solarbe.com/202002/28/321598.html.

16. Wood Mackenzie. Sprint or marathon? China provincial renewable power, competitiveness report 2019 [ EB/OL ] .https://www.woodmac.com/reports/, 2019-08/2019-11.

17. Sohoo, UN: 2009-2019 the cost of photovoltaic kWh plummeted by $81 \%$.

https://www.sohu.com/a/339731001_418320.2019-09 -09 .

18. National energy information platform, photovoltaic industry investment strategy.

https://baijiahao.baidu.com/s?id=1672176734071381 $545 \&$ wfr $=$ spider $\&$ for $=$ pc.2020.-7-14 